\title{
An assessment of the dynamics between the permanent and transitory components of Mexico's output and unemployment
}

\author{
Alejandro Islas C. and Willy W. Cortez
}

ABSTRACT

Previous studies about the relationship between the cyclical components of Mexico's output and unemployment suggest that it closely resembles that found in the economy of the United States of America. This would indicate that the dynamics between output and labour markets in the two economies are rather similar. However, these estimates are puzzling for they do not correspond to a characterization made to Mexico's labour market. Using a methodology first proposed by Clark (1989), we find that the correlation between the transitory components of output and unemployment is much lower than previously thought. Institute of Mexico (ITAM). aislas@itam.mx

Willy W. Cortez, Professor-Researcher C, Department of Quantitative Methods, University Center for Economic and Administrative Sciences (cucea), University of Guadalajara, Jalisco, Mexico. wcortez@cucea.udg.mx 


\section{I}

\section{Introduction}

Between 1987 and 2008, open unemployment rates in Mexico showed wide fluctuations, ranging from 5.2\% in the first quarter of 1987 to 2.6 in the second quarter of 1991 and 8.2 in the third quarter of 1995, when it reached its maximum level. Subsequently, it declined to $2.3 \%$ in the fourth quarter of 2000 and has trended upward since then. These changes in the mean value of unemployment were accompanied by changes in the unemployment volatility, indicating changes in Mexico's labour market dynamics. Between the first quarter of 1987 (1987:Q1) and the fourth quarter of 1994 (1994:Q4), standard deviation in unemployment was about 0.176 , while between 1995:Q1 and 2000:Q4, it increased to about 0.394 . It later declined to 0.148 in $2001: Q 1$ and 2007:Q1.

These fluctuations in unemployment have coincided with output movements in the opposite direction; that is, when unemployment was below its long-term trend, output was above its long-term trend; whereas when unemployment was above, output was below its respective long-term trend. Chavarín (2001) and Loria and Ramos (2007), for instance, have estimated that a 1-percentagepoint change in unemployment was associated with a negative output growth between $2.3 \%$ and $2.7 \%$. The empirical regularity between changes in unemployment and changes in output, also known as Okun's law, is an important building block in Keynesian macroeconomics for it relates output and labour markets. ${ }^{1}$

The usefulness of Okun's law as a policy instrument has been stressed in a number of papers; Knotek (2007), for instance, argues that it can be used as a simple rule of thumb to determine how much unemployment would induce " $\mathrm{x}$ " output growth. It can also help to forecast

$\square$ Professor Numerario III C refers to the appointment that Alejandro Islas C. holds at the Autonomous Technological Institute of Mexico. $\mathrm{He}$ is a full-time, category IIIC, tenured professor and researcher.

Professor-Researcher C refers to the appointment that Willy W. Cortez holds at the University of Guadalajara. He is a full-time, category "C", tenured professor and researcher.

$\square$ The authors are grateful for the useful comments made by staff members of the ECLAC subregional headquarters in Mexico and by participants at the Seminario Aleatorio of the Autonomous Technological Institute of Mexico. Alejandro Islas is grateful to the Asociación Mexicana de Cultura, A.C. for providing support to carry out this work. 1 Prachowny (1993) notes that the aggregate supply curve is derived from the Phillips curve with the help of Okun's law. the unemployment rate. Balakrishnan, Das and Kannan (2010), for their part, use Okun's law as an organizing framework to explain unemployment dynamics for a group of advanced countries during the last recession.

Within this literature, one of the main issues in which economists have been interested has been whether Okun's estimates are stable. A quick review of several studies done for the United States of America, as well as for other developed countries indicates that the coefficient varies significantly across countries and across time periods. There is also evidence that Okun's coefficient is sensitive to the time horizon used to measure the unemploymentoutput relationship, that is, contemporaneous, short run and long run (Weber, 1995).

The variability of the coefficient across countries can be explained by several factors. Blanchard and Quah (1989), for example, argue that Okun's coefficient is a mongrel coefficient because it depends on the type of disturbances that affect the economy, that is, supply or demand shocks. ${ }^{2}$ International studies provide overwhelming evidence that the coefficient does not remain constant. Schnabel (2002) found evidence that during 1990-2000, the coefficient changed significantly in a sample of industrialized countries. The changes, however, were not homogeneous across countries: some countries exhibited higher sensitivity of output growth to unemployment change than others. Cazes, Verick and Al Hussami (2011) and Balakrishnan, Das and Kannan (2010), in turn, present evidence that the 2008 economic crisis has had a different impact on labour markets in countries of the Organisation for Economic Cooperation and Development (OECD); namely, there are countries that have endured a higher change in unemployment rates - like Spain and the United States - while others have had a lower change in unemployment rates, like Germany, Japan and Italy. Recent studies also provide further evidence that Okun's coefficient is not symmetrical; that is, it takes different values in booms and in recessions (Jardin and Gaétan, 2011).

Our knowledge of the dynamics between output and unemployment in the Mexican economy is rather limited. The existing literature maintains that Mexico's Okun's

2 They found that Okun's coefficient is much smaller when the shock comes from the demand side than when it comes from the supply side of the economy. 
coefficient is close to Okun's original calculations for the United States economy (Chavarín, 2001; Loria and Ramos, 2007). However, those estimates are puzzling for they would indicate that Mexico's labour market is as flexible as the United States'. Yet, when looking at different measures of flexibility, Mexico's labour market is one of the most rigid among OECD and Latin American countries. ${ }^{3}$

In a study of 13 Latin American economies, González-Anaya (2002) found that Mexico's Okun coefficient was among the lowest coefficients for Latin American countries. According to his estimates, it was closer to the ones found for Europe and Japan. He argued that this was attributable in part to the greater real-wage flexibility in Mexico.

Two other issues arise in connection with the studies by Chavarín (2001) and Loria and Ramos (2007). First, from a statistical point of view they both use the two-step methodology to estimate Okun's coefficient, which might result in biased and inefficient estimates

3 For instance, according to OECD, Mexico's Employment Protection Strictness Index during the 1990s and 2000s has been 3.1, compared with 0.21 for the United States economy.

\section{II}

\section{Okun's Law}

Okun's purpose for his 1962 paper was to provide an estimate of the cost of unemployment in terms of potential output. Over time, this research agenda has evolved into a fertile ground for discussing the dynamics of output and unemployment and how they are related over the business cycles.

In his seminal paper, Okun (1962) estimated that a 1-percentage-point increase in unemployment would induce a decline in output growth of about $3.3 \%$. Although it has not been noted by many researchers, the underlying assumption for getting a measure of the impact of unemployment on potential output was that the unemployment rate summarizes, - or is correlated to- - the behaviour of other variables such as: average hours worked, participation rates and labour productivity. In other words, unemployment "...can be viewed as a proxy variable for all the ways in which output is affected by idle resources..." (p. 2). This assumption is very important for obtaining and predicting a fixed
(Sinclair, 2009). Second, neither of these studies provides an explanation of how the size of the coefficient may be influenced by Mexico's output and unemployment interrelated dynamics, or by the functioning of the Mexican labour market.

As shall be clear later on, there are a number of issues involved in the estimation of Okun's coefficient. Our task in this study is rather limited in the sense that we are interested in providing a point estimate that is unbiased and efficient. We depart from the conventional two-step procedure by following a methodology first proposed by Clark (1989). In addition, we relate the size of the estimated coefficient to Mexico's labour market conditions and provide a proper explanation of why the estimates are reasonable or acceptable.

This paper is divided into six sections, including this Introduction. Section II outlines some of the studies done to estimate Okun's coefficient, while, in section III, we discuss briefly the nature of the Mexican labour market and the insight provided by Clark's estimation technique. In section IV, we describe the econometric model used to estimate the relationship between output and unemployment. Section V discusses the main results while the last section, section VI, presents some concluding remarks. coefficient between unemployment change and output growth; otherwise, one should not expect this coefficient to be fixed. Furthermore, technical change, changes in labour market institutions, variations in participation rates and demographic shifts, among other things, would induce changes in the coefficient.

An important conclusion derived from the existing literature is that the relationship between the cyclical components of output and unemployment is rather complex and unstable for it depends on a number of variables and as such we should not expect it to be identical across countries. ${ }^{4}$ To explain the latter, let us define unemployment as the difference between labour supply and labour demand for a given wage rate, then changes in unemployment are induced by changes in

4 Lee (2000), in a study for OECD countries, found that Okun's estimates are also sensitive to the choice of models (including the first difference and the gap specifications). 
either labour supply or demand or both. Labour supply, on the one hand, depends on demographic variables and labour market institutions. ${ }^{5}$ Labour demand, on the other hand, depends on technical progress and on the conditions prevailing in the goods market. In the short run, actual employment would also depend on firms' capacity to adjust the number of hours put in by workers and their work force's productivity. Thus, it is not clear whether a change in output demand would automatically induce a change in employment hence, in unemployment. For instance, if we assume that there is an increase in aggregate demand and if the higher demand is met with an increase in the number of hours worked and/or higher labour productivity, then employment (unemployment) would not necessarily increase (decrease). A priori, we cannot say how fast those variables would adjust across countries and over time. But we know that they will not adjust uniformly across countries.

It is customary to present Okun's law in terms of the impact that a one-percentage-point change in unemployment would have on the output growth rate. However, from a Keynesian perspective, unemployment depends on goods market conditions. In other words, unemployment is the dependent variable while output is the independent one. ${ }^{6}$ In the past, economists would run unemployment on output and then assume that Okun's coefficient was the inverse of the estimated parameter. We now know that this procedure is incorrect because, as we argued above, not only is the relationship between them non-linear but it is also probable that they measure different things. Barreto and Howland (1993) were among the first to notice this. They maintained that one should seriously consider the direction of the regression. They indicated that Okun erroneously assumed that it was possible to track the relationship in both ways. Specifically, $\Delta u=f(\Delta y)$ may be related to demand and/ or supply shocks, while $\Delta \mathrm{y}=g(\Delta u)$ may be associated to supply and demographic shocks. Thus, from a theoretical point of view, there is no reason for us to expect that the two coefficients have any arithmetic or algebraic relationship. It should be noted that this is independent of the feedback effect that emerges between them.

Within Okun's literature, we identify three techniques of estimation: (i) Estimation of Okun's coefficient using the conventional two-step procedure; (ii) the estimation

5 Demographic variables are, for example, population growth, women's participation in the labour market, while labour market institutions include factors that affect workers' preferences about work-leisure trade-off, employment protection legislation, habits and work effort among others.

6 In Keynes' view, labour demand is a derived demand. of Okun's coefficient as part of a bivariate model where the cyclical component is estimated jointly with the trend component, (iii) estimation of Okun's coefficient assuming that it varies over time.

The conventional estimation of Okun's coefficient involves a two-step procedure. The first step consists in removing the permanent component of the series and the second step in estimating the correlation between the transitory components of output and unemployment. The permanent component of the series is usually obtained through the use of different techniques, which range from estimating the trend component by ordinary least squares (OLS), to using the Hodrick-Prescott filter. In some cases, the unobserved permanent component has been simply eliminated by taking the first differences of the series 7 . Once the (unobserved) permanent component has been estimated, the transitory component is obtained by subtracting the permanent component from the observed series. The second step involves estimating Okun's coefficient by oLs.

Sinclair (2009) maintains that this methodology provides a biased and inefficient coefficient for two reasons. First, since the permanent and the transitory components of the two series are correlated, it is more efficient to jointly estimate their cyclical components. Second, to the extent that the measurement error of the independent variable is correlated with the measurement error of the dependent variable, oLs estimates are biased and inconsistent. Thus, a better approach would be to use the estimate of the correlation rather than the correlation of the estimates.

Bivariate models that estimate jointly the permanent and transitory elements of unemployment and output began as a reaction to Nelson and Plosser's (1982) methodology to remove non-stationarity by first differencing, making the trend a random walk with drift rather than a straight line. Clark (1987) points out that two shortcomings of this approach are, first, tests for non-stationarity in trend have very little power against plausible alternatives; second, the analysis is based on the strong assumption that the auto-covariance function for the first difference of output is exactly zero after lag one.

Clark (1987) proposed a new analysis of United States output by decomposing the series into its two unobserved independent components: the non-stationary trend and the stationary cyclical components. The framework for his analysis is the state space model, which allows for a more general specification of the trend component.

7 When one of the series is stationary, i. e., $\mathrm{I}(0)$, then the first step might be redundant. 
Clark (1989), on the other hand, uses the Kalman filter and maximum likelihood to estimate the non-stationary permanent and stationary cyclical components of output growth and unemployment for six developed economies. ${ }^{8}$ He finds strong evidence that the estimated output's stationary component is closely related to unemployment's cyclical component. Evans (1989), for his part, uses a bivariate vector autoregressive (VAR) model to describe output-unemployment dynamics, to estimate the degree of persistence in output innovations, and to decompose output into trend and cycle. He concludes that a bivariate analysis indicates the existence of feedback between unemployment and output growth as well as a negative contemporaneous correlation between output growth and unemployment innovations.

The discussion about the relationship between the transitory and permanent components of real gross domestic product (GDP) is important because it allows us to determine whether the observed GDP variability is the result of the variability of the permanent or transitory components. Furthermore, it can also help us estimate the cross series relationships between the permanent component and the transitory components.

The third technique of estimation is related to the fact that the coefficient has not remained constant over time. Since the mid-1990s, an increasing number of studies have investigated whether Okun's coefficient is unstable or not. Prachowny (1993), for example, argues that the 3:1 ratio of output to unemployment holds only because other factors like weekly hours, induced labour supply and productivity tend to rise as well. An important conclusion of Prachowny's paper is that if any of these other factors change then, other things being equal, the coefficient linking output to unemployment should change as well.

Knotek (2007) and Balakrishnan, Das and Kannan (2010), among others, present evidence that, contrary to the findings of previous studies, the relationship

8 These economies were Canada, France, Germany, Japan, United Kingdom of Great Britain and Northern Ireland and United States. between output and unemployment has not remained stable. In a study on the United States economy during 1960-2007, Knotek found that Okun's coefficient has fluctuated between -0.067 in 1975 to about -0.088 in 1995 to -0.04 in 2007 ; that is, the coefficient has significantly increased during the 2000s.

Balakrishnan, Das and Kannan (2010) investigated unemployment dynamics for a number of industrialized countries between 1980 and 2008. They found that Okun's coefficient changed significantly among OECD countries. In particular, they observed that for Sweden and the United Kingdom of Great Britain and Northern Ireland the coefficient steadily increased (in absolute values), while for Germany and the United States it fluctuated with no clear pattern. They argue that institutional changes in labour markets and technological as well as demographic changes induced the changes that the coefficient shows for this group of developed countries. A recent study by Cazes, Verick and Al Hussami (2011) presents evidence that the impact on unemployment of the financial crisis of 2008 has been different between the United States and the European countries. These differentiated effects are due to the different evolution of Okun's coefficient in these countries.

An additional conclusion of their studies is that the impact of output fluctuations on unemployment is asymmetrical; that is, the coefficient behaves differently during recession than during recoveries. Crespo (2003) found that for the United States economy the contemporaneous effect of growth on unemployment is significantly higher in recessions than in expansions. $\mathrm{He}$ also found that shocks to unemployment tend to be more persistent in the expansionary regime. Jardin and Gaétan (2011), in turn, in a study for 16 European countries found evidence that unemployment responds more strongly to output growth when the economy is contracting than when it is expanding.

In the next section, we discuss some of the main characteristics of Mexico's labour market and present the two contrasting views about its nature. This section is important for it will help us understand the empirical results. 


\section{III}

\section{How flexible is Mexico's labour market?}

Common sense suggests that the magnitude of Okun's coefficient is a reflection of the labour market dynamics imposed by the country's institutional framework and technical change. We can classify the studies on the nature of Mexico's labour market into two types according to the view on which they are based. On the one hand, there is the view that Mexico's labour market is heavily regulated by laws that impede employment creation. In this case, output growth would not necessarily translate into large unemployment variations but rather into real wage changes (Heckman and Pagés, 2000, and Gill, Montenegro and Dömeland, 2001). In times of recession and because of the rigidity of the federal labour law and unions, it would be extremely difficult for firms to lay-off workers. ${ }^{9}$ It is also argued that job security provisions (which include severance payments) increase dismissal costs to the firms. These costs discourage firms from firing workers whenever there is a negative shock and from increasing job creation in expansions. Heckman and Pagés (2000) found that Mexico exhibits one of the highest indices of job security within Latin American countries, which implies that it has one of the most regulated labour markets in the region. ${ }^{10}$ Assuming that these rigidities operate during expansions as well as during recessions, one would expect a low correlation between the transitory components of output and unemployment; that is, one would expect a low Okun's coefficient.

A contrasting view is that since the mid-1980s, when Mexico began its new development strategy based on trade and economic liberalization, an increasing number of firms have adopted new mechanisms that enable them to adjust better to economic fluctuations (De la Garza, 2005). Among these schemes there is the increased use of short term contracts and outsourcing as a means of reducing labour costs that result from job stability. This is particularly true for the maquila ${ }^{11}$ and service sectors, the fastest growing sectors within

9 On December 2012, the Mexican Congress approved new labour legislation that provides much more flexibility to firms to hire and fire workers.

${ }^{10}$ OECD also found evidence that among OECD members, Mexico has the highest employment protection index for both types of contract (permanent and temporary).

11 The maquila sector is composed of assembly plants whose output is intended mainly for export. the Mexican economy since the late 1980s (Marshall, 2004). This view therefore, would suggest that Okun's coefficient is large enough so that variations in output growth would induce significant variations in unemployment rates.

Implicit in this debate is the recognition of the existence of a large informal sector which provides employment to about half of Mexican employed workers (Loayza and Sugawara, 2009). Even though informality is an unobservable variable, the size of the informal labour market has been estimated by indirect means. ${ }^{12}$

Calderon (2000) found that there is a close integration between Mexico's formal and informal labour markets. More recent studies by Alcaraz, Chiquiar and RamosFrancia (2008) and Alcaraz (2009) corroborate the idea of a close interaction between the two markets. These authors found evidence that the transition rate between formal and informal employment is higher than the one between manufacturing and service sectors. They point out that this higher mobility between formal and informal sectors would indicate the existence of institutional labour market rigidities in Mexico's formal sector.

In section II, we provided an explanation of why under certain circumstances changes in output would not translate into changes in unemployment (and vice versa). The existence of a large informal labour market closely interrelated to the formal one means that there is an additional channel through which output fluctuations would not necessarily translate into fluctuations in open unemployment, or vice versa. In other words, the existence of a large informal labour market would modify the expected relationship between the cyclical components of output and unemployment. Instead, we may observe that a given change in output would induce higher labour mobility between the formal and informal sectors while the unemployment rate remains constant. Consider, for example, decomposing employment rate into formal employment rate $\left(e_{f}\right)$ and informal employment rate $\left(e_{i n f}\right)$, then the following should be true:

$$
\begin{aligned}
\mathrm{u} & =1-e_{f}-e_{i n f} \\
\Delta \mathrm{u} & =-\Delta e_{f}-\Delta e_{i n f}
\end{aligned}
$$

\footnotetext{
12 For a brief description of some of these methods, see Loayza and Sugawara (2009).
} 
If formal employment is heavily regulated, then variations in unemployment would be mostly absorbed by variations in informal employment. Furthermore, given that Mexico's official labour statistics do consider informal employment as employment, the correlation between variations in output and unemployment would be fairly low, unless the informal sector is not flexible enough. ${ }^{13}$ This is true even in the light of the institutional rigidities mentioned by Heckman and Pagés (2000). Okun himself noted that the value of the coefficient depended on a set of strong assumptions about the behaviour of labour productivity, average hours worked and participation rates. ${ }^{14}$

13 Or the relative importance of the informal sector is rather small.
Having discussed the relationship between the transitory components of unemployment and output, there remains the question of what to expect about the relationship between the permanent components of both series. We expect that the long-run equilibrium relationship is measured by the correlation between the permanent components of both series. In this sense, Okun's coefficient will be smaller because in the long run a number of variables would not remain fixed as in the case of the capital utilization, technology and participation rates and labour productivity.

14 So, if any of these variables change, then the coefficient should not be expected to remain constant but rather to change over time.

\section{IV}

\section{A model for the output and unemployment rate}

In this section, we follow the permanent-transitory components model for output and unemployment rates developed by Clark (1989) and Sinclair (2009):

$$
\begin{gathered}
y_{t}=\tau_{y_{t}}+c_{y_{t^{\prime}}} \\
\tau_{y_{t}}=\mu_{y}+\tau_{y_{t-1}}+\eta_{y_{t^{\prime}}} \\
u_{t}=\tau_{u_{t}}+c_{u_{t^{\prime}}} \\
\tau_{u_{t}}=\mu_{u}+\tau_{u_{t-1}}+\eta_{u_{t}}
\end{gathered}
$$

In this model, the output $\left(y_{t}\right)$ and the unemployment rate $\left(u_{t}\right)$ are the sum of two components. The first component $\left(\tau_{i_{t}}, i=y, u\right)$ is the permanent component which is the steady-state level after removing all temporary movements. The second component $\left(c_{i}, i=y, u\right)$ is the transitory component that expresses all temporary movements and is assumed to be stationary. Each of the trend components is assumed to be a random walk to allow for permanent movements in the series. The transitory component $\left\{\left(c_{y_{t}}, c_{u_{t}}\right)\right\}$, on the other hand, is a stationary bi-variate stochastic process.

To complete the characterization of output and unemployment rates, we assume that the transitory deviations from the equilibrium values are driven by a stationary $\operatorname{VAR}(\mathrm{p})$ process,

$$
\Phi(L) \underline{c_{t}}=\underline{\varepsilon_{t}}
$$

$$
\begin{aligned}
\text { where } c_{t} & =\left(\begin{array}{l}
c_{y_{t}} \\
c_{u_{t}}
\end{array}\right), \\
\underline{\varepsilon_{t}} & \left.=\left(\begin{array}{l}
\varepsilon_{y_{t}} \\
\varepsilon_{u_{t}}
\end{array}\right) \stackrel{i . i . d}{\sim}\left(\begin{array}{l}
0 \\
0
\end{array}\right),\left(\begin{array}{cc}
\sigma_{\varepsilon_{y}}^{2} & \rho_{y} \sigma_{\varepsilon_{y}} \sigma_{\varepsilon_{u}} \\
\rho_{u} \sigma_{\varepsilon_{y}} \sigma_{\varepsilon_{u}} & \sigma_{\varepsilon_{u}}^{2}
\end{array}\right)\right)
\end{aligned}
$$

and $\Phi(L)$ is a two-dimensional lag polinomial of order $\mathrm{p}$.

\section{An autoregressive (AR(2)) transient dynamics}

Following a tradition in the unobserved components literature the cyclical component is modelled as an autoregressive (AR(2)) process, since it facilitates the constraint that the roots of the AR polynomial stay outside the unit circle during the maximum likelihood estimation (see for instance, Morley, Nelson, and Zivot, 2003; Clark, 1987 and 1989; and Watson, 1986). ${ }^{15}$ The AR(2) model is obtained from (5) by setting

15 A theoretical justification for the AR(2) cycle for unemployment follows from Alogoskoufis and Manning (1988), who argue that the unemployment rate for all countries should be modelled by an $\mathrm{AR}(2)$. 
$\phi_{y}(L)=1-\phi_{1 y} L-\phi_{2 y} L^{2}, \phi_{u}(L)=1-\phi_{1 u} L-\phi_{1 u} L^{2}$. We assume the innovations $\left(\eta_{y t}, \eta_{u t}, \varepsilon_{y t}\right.$, and $\left.\varepsilon_{u t}\right)$ are normally distributed random variables with mean zero and general covariance matrix —allowing possible correlation between any of the components.

The unobserved component model can be estimated by using state space techniques to find the likelihood function of the sample. If the error terms are assumed to be normally distributed, then the parameters of the model can be estimated employing maximum likelihood techniques. For instance, parameter estimates in the above system can be obtained by starting with an initial guess for the state vector and its covariance matrix. Given the initial estimated parameters, the Kalman filter recursively generates the prediction equations. Ultimately, the Kalman filter generates both unobserved components $\left(\tau_{i_{t}}, i=y, u\right)$ and $\left(c_{i_{i}}, i=y, u\right)$. A special feature of the state-space system is that the transition matrix has two unit roots - corresponding to the two stochastic trends. Therefore the covariance matrix of the initial value of the state vector will be unbounded. Hence, care has to be taken with regards to the initialization of the state vector. We deal with this problem through the initialization method developed by Koopman (1997) and refined in Durbin and Koopman (2001). ${ }^{16}$

It may not be immediately obvious that the unobserved component model is identified. However, through a reduced form representation of the model, in a number of papers (see for instance, Schleicher, 2003; Morley, Nelson and Zivot, 2003; Morley, 2007), it is shown that an unobserved component model with correlated innovations is identified, provided that it has sufficiently rich dynamics. Schleicher (2003) presents a general discussion of a number of technical issues involved in the identification and estimation of a multivariate, correlated, unobserved components model. He shows that, in general, the requirement for identification of a structural unobserved component model with non-common trends and non-common cycles, where the transitory components are modelled as $\operatorname{AR}(\mathrm{p})$ cycles, is: $p \geq 1+\frac{1}{n}$. Therefore, for a multivariate case, $\operatorname{AR}(2)$ cycles will result in an implicit over-identification restriction. It should be noted that, even though the correlated unobserved component model is identified, weak identification could still be an

16 For the unobserved component model, the diffuse initial state vector can be defined as $\alpha_{1 \mid 0}=\left[\begin{array}{l}\delta_{k x 1} \\ 0_{2 l x 1}\end{array}\right]+v_{0}$ where $\delta \sim N\left(0, k I_{2}\right), k \rightarrow \infty$. The covariance matrix of the initial state vector, $P_{1 / 0}$ can be split into an unbounded component $k P_{\infty}$ pertaining to the stochastic trends and a bounded component associated with the stationary component $P_{*}$. issue. Weak identification is a problem because it can lead to distorted inferences using estimated standard errors. Nelson and Startz (2007) show that the true variance goes to infinity in the limit of non-identification, but that the sample variance remains finite. They suggest using likelihood ratio statistics instead of Wald statistics for hypothesis testing when identification is a potential problem.

The random-walk-AR(2) model implies the following moments:

$$
\begin{aligned}
& \operatorname{Var}\left(c_{y_{t}}\right)=\frac{\left(1-\phi_{2 y}\right) \sigma_{\varepsilon_{y}}^{2}}{\left(1+\phi_{2 y}\right)\left[\left(1-\phi_{2 y}\right)^{2}-\phi_{1 y}^{2}\right]^{\prime}} \\
& \operatorname{Var}\left(c_{u_{t}}\right)=\frac{\left(1-\phi_{2 u}\right) \sigma_{\varepsilon_{u}}^{2}}{\left(1+\phi_{2 u}\right)\left[\left(1-\phi_{2 u}\right)^{2}-\phi_{1 u}^{2}\right]^{\prime}}
\end{aligned}
$$

and

$$
\frac{\left(1-\phi_{2 y} \phi_{2 u}\right) \sigma_{\varepsilon_{y} \varepsilon_{u}}}{1-\phi_{1 y} \phi_{1 u}\left(1+\phi_{2 y} \phi_{2 u}\right)-\phi_{2 y}\left(\phi_{1 y}^{2}+2 \phi_{2 y}\right)-\phi_{2 y} \phi_{1 u}^{2}+\phi_{2 y}^{2} \phi_{2 u}^{2}}
$$

Let us look at these issues in the context of Okun's law. Okun suggested that there was a strong link between the output gap and the unemployment gap. Since the relationship is indigenously bidirectional, researchers have been juggling the equations and have regressed both, output on unemployment (e.g. Freeman, 2001) and vice versa (e.g., Sögner and Stiassny, 2000). Yet, the interpretation of the results frequently misguided the authors and Okun himself, which leads to spurious results.

As argued, the relationship between real output and the unemployment rate is not necessarily linear. Separate regressions should therefore be run: output on unemployment and unemployment on output; thus,

or

$$
y_{t}-y^{*}{ }_{t}=\lambda\left(u_{t}-u_{t}^{*}\right)+\vartheta_{t}
$$

$$
u_{t}-u^{*}{ }_{t}=\theta\left(y_{t}-y^{*}{ }_{t}\right)+\zeta_{t}
$$

where $\left(y_{t}-y^{*}\right)$ and $\left(u_{t}-u^{*}\right)$ are the transitory components of output and unemployment rate, respectively, and $\vartheta_{t}, \zeta_{t}$ represent the random errors. The best linear predictor of the unemployment rate given output can be found by regressing unemployment on gross national product (GDP) (see equation 10), while any attempt to predict output given unemployment requires that GDP be regressed on unemployment (see equation 9). 
It is customary to use $\lambda$ to represent Okun's coefficient. As already pointed out, the conventional estimation of Okun's law has two consequences. First, OLS estimates are biased and inconsistent, and since $\lambda$ is negative, $\lambda$ will tend to overestimate $\lambda$. Second, since the two components are correlated, it is more efficient to estimate both cyclical components jointly. In our model $\lambda$ and $\theta$ are obtained as

$$
\lambda=\frac{\operatorname{Cov}\left(c_{y_{t}}, c_{u_{t}}\right)}{\operatorname{Var}\left(c_{u_{t}}\right)}
$$

and

$$
\theta=\frac{\operatorname{Cov}\left(c_{y_{t}}, c_{u_{t}}\right)}{\operatorname{Var}\left(c_{y_{t}}\right)}
$$

respectively.

\section{Empirical results}

\section{The data}

The key variables are unemployment and production. The figures for Mexico's gross domestic product were obtained from the National Institute of Statistics and Geography (INEGI), ${ }^{17}$ and are calculated on a quarterly basis in real pesos $($ base year $=2003$ ). The unemployment series was obtained from the National Survey on Urban Employment (ENEU) and the National Survey on Occupation and Employment, (ENOE), conducted by INEGI. ${ }^{18}$ The data are representative of the urban areas in Mexico, which account for about a third of the population. ${ }^{19}$ All data are quarterly, seasonally adjusted and cover the period 1987: QI to 2008: Q4.

Figure 1 shows the behaviour of the variables used in the analysis. High unemployment rates in the late 1980s and mid-2000s were accompanied by relatively low and slowly growing production levels. The Mexican financial crisis of 1994 and the global crisis of 2008 dramatically raised unemployment and slashed output levels. The average rate of unemployment for the period $1987-2008$ is about $4.99 \%$ with minimum and maximum values of $3.06 \%$ and $9.03 \%$, respectively. During the early 1990s, the unemployment rate showed a slight upward

\footnotetext{
17 INEGI performs statistical work comparable to that done in the United States by the Census Bureau, Bureau of Labor Statistics, and Bureau of Economic Analysis.

18 Unemployment data from 1987-I to 2004-4 are from ENEU, standardized by ENOE criteria.

19 Approximately $70 \%$ of the Mexican population lives in urban areas. Moreover demographic and labour market conditions are very different across the urban and rural sectors so the results of this paper must be considered with this in mind.
}

trend and reached its highest value by the end of 1995 . In 1996, it started to decline rapidly, so that by the end of 2000, it had reached its lowest level. This decline in the unemployment rate was short-lived for in the next year unemployment began a new upward trend; this last upward trend in the Mexican unemployment rate could be related to the slowdown in the United States economy in 2001, which worsened after the September 11 terrorist attacks, and hit Mexico's economy hard. Real GDP growth dropped from $6.6 \%$ in 2000 to $0.2 \%$ in 2001.

We now turn to the estimation of our econometric model.

\section{Unit root test}

Before estimating the permanent and transitory components of each time series employing the unobserved component model, we need to check if the series are stationary or not. Given that the period of analysis includes the 1994 Mexican financial crisis and the recovery during the second half of the Zedillo administration as well as the 2001 Mexican recession and the fall in growth rates during the Fox administration, we use the endogenous Lee and Strazicich (2003) minimum Lagrange multiplier unit root test with two structural breaks. The data used are the log of real GDP multiplied by $100\left(y_{t}\right)$ and the unemployment rate $\left(u_{t}\right)$. Results of the unit root test using level data are shown in table 1 . We fail to reject the null hypotheses that there exists a unit root for each series. This implies that each time series then follows a unit root process and therefore they are not stationary in levels. This is the desired condition, so the proposed unobserved component model can be implemented. 
FIGURE 1

Mexico: real GDP and unemployment, first quarter 1987 - fourth quarter 2008

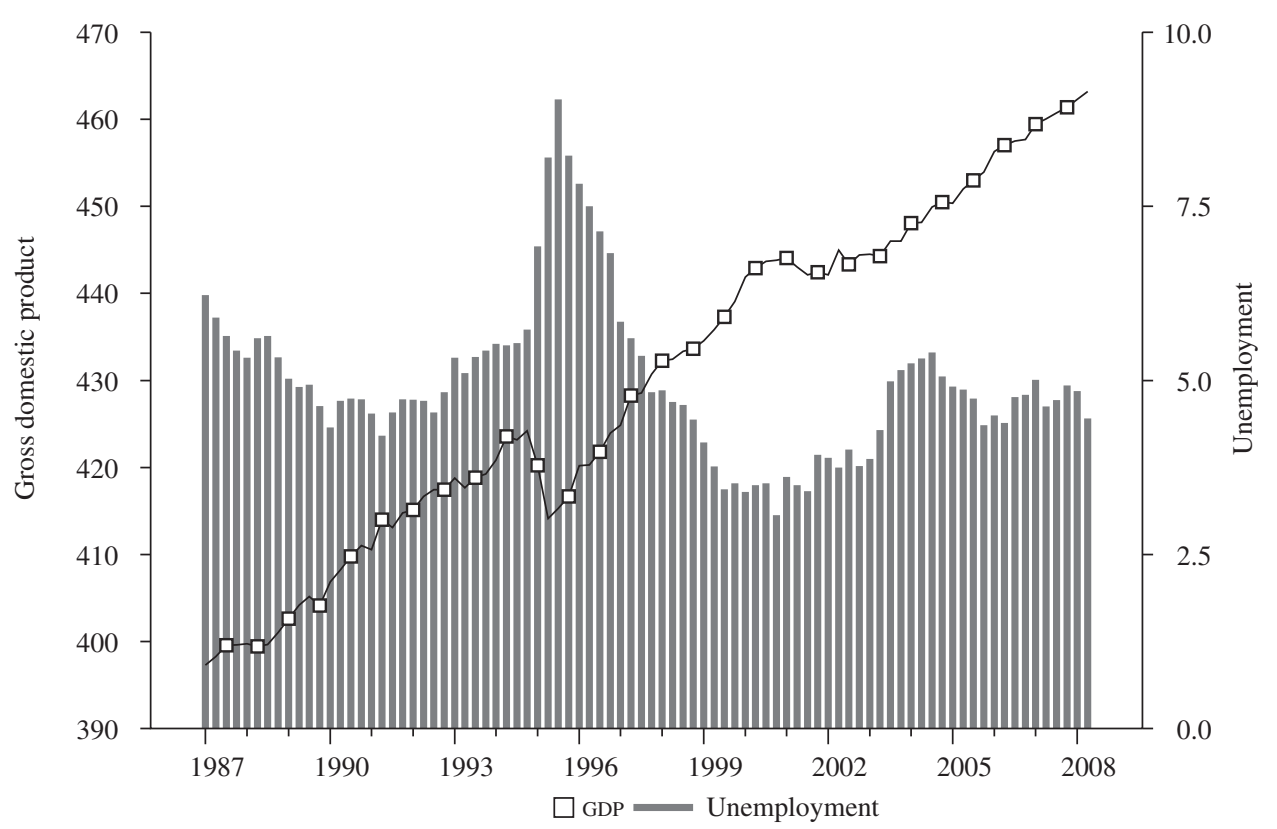

Source: National Institute of Statistics and Geography (INEGI) of Mexico.

TABLE 1

The endogenous two-break Lagrange multiplier unit root test

Log (GDP). Model C: $\mathrm{K}=1, T_{B_{1}}=1994: 4, T_{B_{2}}=2000: 1, \mathrm{~N}=88, \lambda_{1} \cong 0.3, \lambda_{2} \cong 0.6$

Critical values $5 \%(-5.74) t_{\emptyset}=-3.5403$

\begin{tabular}{lccccccc}
\hline Parameter & $\mu$ & $d_{1}$ & $d_{t_{1}}$ & $d_{2}$ & $d_{t_{2}}$ & $\phi$ \\
Estimator & 0.758 & -4.123 & -0.596 & 1.177 & 1.782 & -0.2739 \\
T-statistics & $3.5403^{*}$ & $-3.2122^{*}$ & $-1.4205^{* *}$ & 0.930 & $3.305^{*}$ & -3.5403 \\
\hline
\end{tabular}

Unemployment model $\mathrm{C}: \mathrm{K}=1, T_{B_{1}}=1995: 1, T_{B_{2}}=1999: 4, \mathrm{~N}=88, \lambda_{1} \cong 0.4, \lambda_{2} \cong 0.6$

Critical values $5 \%(-5.67) t_{\varnothing}=-2.865$

\begin{tabular}{lrrrrrrrr}
\hline Parameter & $\mu$ & $d_{1}$ & $d_{t_{1}}$ & $d_{2}$ & $d_{t_{2}}$ & $\phi$ & 0.393 & -0.188 \\
Estimator & -0.252 & 1.555 & 0.023 & 0.249 & 0.183 & $4.120^{*}$ & -2.865 \\
T-statistics & $-2.302 *$ & $4.997^{*}$ & 0.184 & 0.783 & \\
\hline
\end{tabular}

Source: prepared by the author.

$*$, ** denotes significance at $5 \%$ and $10 \%$ respectively.

Null: $y_{t}=\mu_{0}+d_{1} B_{1 t}+d_{t 1} D_{1 t}+\mathrm{d}_{2} B_{2 t}+d_{t 2} D_{2 t}+y_{t-1}+v_{1 t}$

Alternative: $y_{t}=\mu_{1}+\Upsilon t+d_{1} D_{1 t}+d_{t 1} D T_{1 t}+\mathrm{d}_{2} D_{2 t}+d_{t 2} D T_{2 t}+v_{2 t}$

Where $D_{j t}=1$ for $t \geq T_{B j}+1, \mathrm{j}=1,2$ and 0 otherwise; $D T_{j t}=t-T_{B j}$ for $t \geq T_{B j}+1, j=1,2$ and 0 otherwise; $B_{j t}=1$ for $t=T_{B j}+1, j=1,2$, and 0 otherwise $T_{B j}$ denotes a time period when a break occurs. 


\section{Maximum likelihood estimates}

Using the Kalman Filter, we estimate the unobservedcomponent model for output and unemployment rate by maximum likelihood. Table 2 reports the estimates and asymptotic standard errors, while figures 2 and 3 plot the estimated temporary components of the logs of real GDP and the unemployment rate respectively, along with their unobserved permanent components. They are produced using the Kalman smoother, which uses all information available in the sample, thus providing a better "in sample" fit compared with the basic Kalman filter, which only uses information available at time t. The drift $\left(\mu_{y}\right)$ in the permanent component of output was significant while the drift in unemployment rates was not so and is not included in the report. We included a structural break in the drift term in the fourth quarter of 1994 for the $\log$ of real GDP. Some results are worth mentioning.

First, innovations to the permanent component of output have considerable impact and are stronger than similar shocks on the permanent component of unemployment. Both supply and demand side shocks seem to have important effects on output performance. Open unemployment, owing to the existence of a rigid labour law and a large informal labour market, is less sensitive to external shocks.

Second, innovations to the permanent components are significant and negatively correlated with innovations to the transitory components in both real GDP and unemployment rates. Also, the estimates of the autoregressive parameters are relatively small, suggesting that most of the persistence of both series is captured in the permanent component. As we can observe in table 2, most of the movements for real GDP and the unemployment rate appear to stem from permanent shocks.

Third, unlike output, the volatilities of the permanent and temporary components of unemployment are rather equal. This would suggest that external shocks to the labour market affect equally both its temporary and permanent components. However, these impacts are much lower than the ones that affect output.

Maximum likelihood estimates of the trend AR(2) model a

\begin{tabular}{|c|c|c|c|c|c|}
\hline Parameter & Estimated & Parameter & Estimated & Parameter & Estimated \\
\hline \multicolumn{2}{|c|}{ Real GDP } & \multicolumn{2}{|c|}{ Unemployment rate } & \multicolumn{2}{|c|}{ Cross-series correlation } \\
\hline$\sigma_{\eta_{y}}$ & $\begin{array}{c}1.8487 \\
(0.3067)\end{array}$ & $\sigma_{\eta_{\mathrm{u}}}$ & $\begin{array}{c}0.5141 \\
(0.1067)\end{array}$ & $\rho_{\eta_{y} \eta_{u}}$ & $\begin{array}{l}-0.7977 \\
(0.0670)\end{array}$ \\
\hline$\sigma_{\varepsilon_{y}}$ & $\begin{array}{c}0.8311 \\
(0.2676)\end{array}$ & $\sigma_{\varepsilon_{\mathrm{u}}}$ & $\begin{array}{c}0.5105 \\
(0.1209)\end{array}$ & $\rho_{\eta_{\mathrm{y}} \varepsilon_{\mathrm{u}}}$ & $\begin{array}{c}0.7207 \\
(0.0816)\end{array}$ \\
\hline$\rho_{\eta_{\mathrm{y}} \varepsilon_{\mathrm{y}}}$ & $\begin{array}{l}-0.8151 \\
(0.1166)\end{array}$ & $\rho_{\eta_{u^{u}} \varepsilon_{u}}$ & $\begin{array}{l}-0.9929 \\
(0.0054)\end{array}$ & $\rho_{\eta_{u} \varepsilon_{y}}$ & $\begin{array}{c}0.9995 \\
(0.0054)\end{array}$ \\
\hline$\mu_{y_{1987-1994}}$ & $\begin{array}{c}0.7232 \\
(0.1212)\end{array}$ & $\phi_{1_{\mathrm{u}}}$ & $\begin{array}{c}0.3267 \\
(0.1915)\end{array}$ & $\rho_{\varepsilon_{\mathrm{y}} \varepsilon_{\mathrm{u}}}$ & $\begin{array}{l}-0.9890 \\
(0.0338)\end{array}$ \\
\hline$\mu_{y_{1995-2010}}$ & $\begin{array}{c}0.7982 \\
(0.1903)\end{array}$ & $\phi_{2_{\mathrm{u}}}$ & $\begin{array}{l}-0.0668 \\
(0.0967)\end{array}$ & & \\
\hline$\phi_{1 y}$ & $\begin{array}{c}0.4479 \\
(0.1673)\end{array}$ & & & & \\
\hline$\phi_{2 y}$ & $\begin{array}{l}-0.4000 \\
(0.1098)\end{array}$ & & & & \\
\hline
\end{tabular}

Log likelihood $=-158.2011$

Source: prepared by the author.

a Where $\sigma_{\eta_{i}} ; i=y, u$ is the standard deviation of permanent innovation. $\sigma_{\varepsilon_{i}} ; i=y, u$ is the standard deviation of temporary innovation. $\rho_{\eta_{i}} \varepsilon_{i} ; i=y$, $u$ is the correlation between innovations. $\rho_{\eta_{y} \eta_{u}}$ is the correlation between permanent unemployment and permanent GDP. $\rho_{\eta_{y} \varepsilon_{u}}$ is the correlation between permanent GDP and transitory unemployment. $\rho_{\eta_{u} \varepsilon_{y}}$ is the correlation between permanent unemployment and transitory GDP. $\rho_{\varepsilon_{y} \varepsilon_{u}}$ is the correlation between transitory GDP and transitory unemployment. $\phi_{j i} ; i=y, u ; j=1,2$ are the AR(2) model parameters. 
FIGURE 2

Mexico: real GDP and the estimated components,

first quarter 1987 - fourth quarter 2008

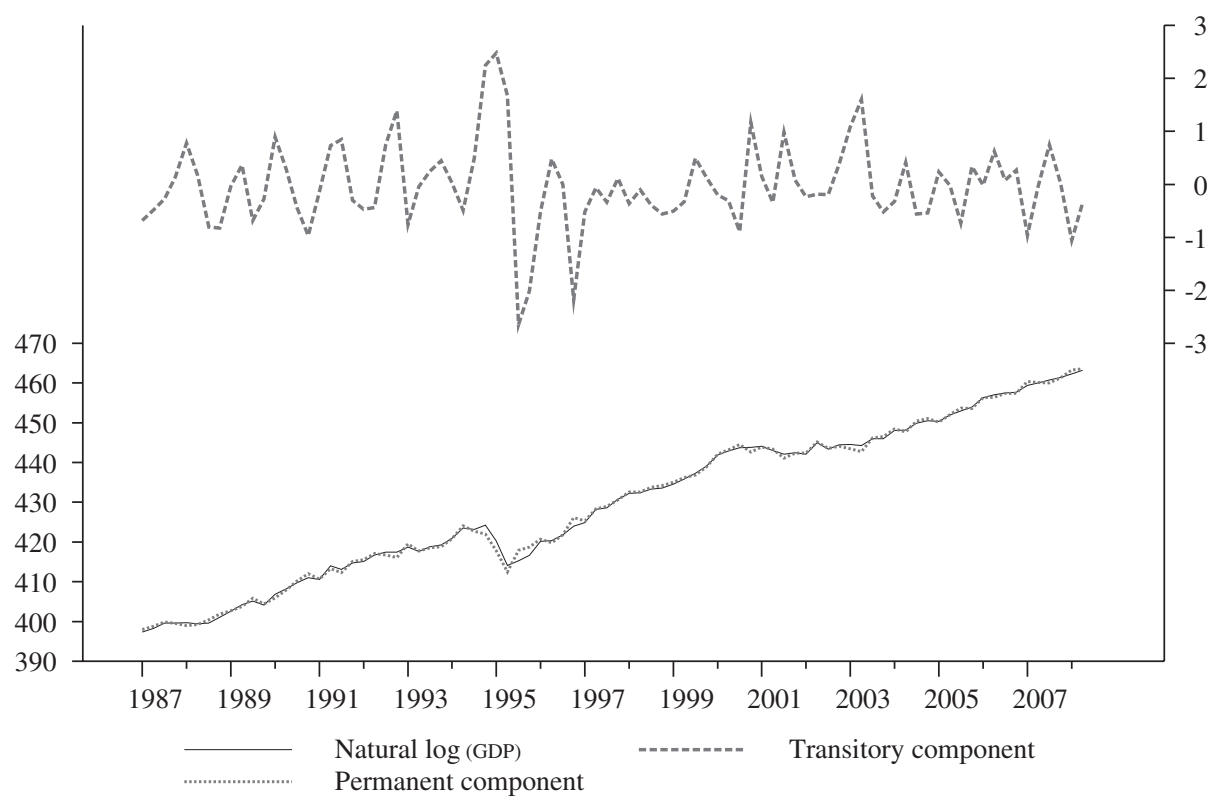

Source: prepared by the author.

FIGURE 3

Mexico: unemployment rate and estimated components,

first quarter 1987 - fourth quarter 2008

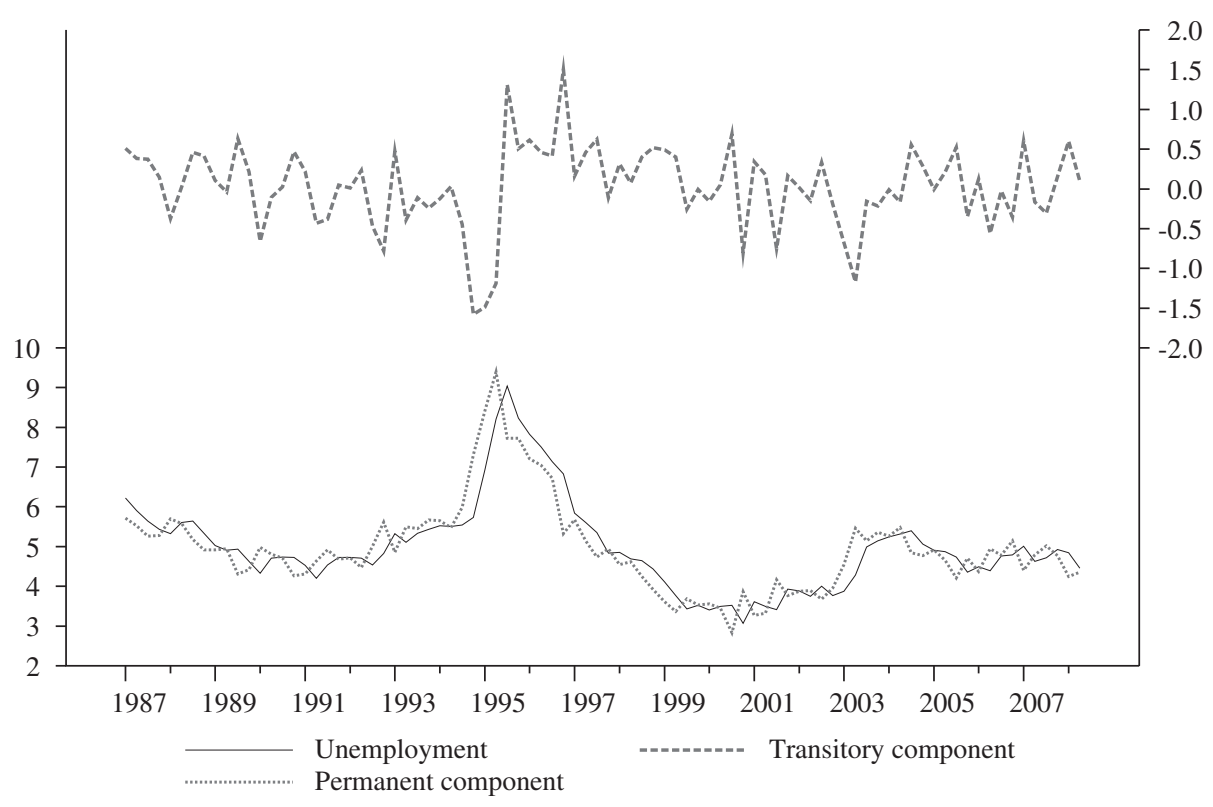

Source: prepared by the author. 
A closer examination of figure 3 would indicate that at the beginning of the 1994 Mexican financial crisis, the unemployment rate started to rise, but our estimates suggest that the permanent level of the unemployment rate rose faster in anticipation of future increases in the unemployment rate. We observe the same behaviour at the beginning of 2001 when the permanent component of unemployment rose faster, anticipating the negative effect of the United States recession on the Mexican economy.

Fourth, as Okun's law suggests, the transitory components of output and the unemployment rate are negatively correlated. Even though our results suggest that most of the fluctuations in both real GDP and the unemployment rate are due to movements in the permanent components, it is still important to consider the relationship between their transitory components.

Equation (9) is relevant for answering the following question: Given a certain level of unemployment, what level of GDP should one expect under the economic conditions prevailing during the sample period? To answer this question, we estimate Okun's coefficient through equation (11) to obtain:

$$
\lambda=-1.657 \text { (standard deviation: } 0.842 \text { ) }
$$

which implies that a 1-percentage-point decrease in transitory unemployment corresponds to a 1.6 percentagepoint increase in transitory real GDP. Our estimates of Okun's coefficient $(\lambda)$ is, therefore, much lower than previous ones.

Several possible phenomena could explain this lower coefficient. First of all, the estimation assumes that the number of working hours and labour productivity move at the same pace as unemployment. However, if any of these variables change at a different rate, then one should expect the coefficient to be lower. Unfortunately, we do not have reliable data on either variable to control for these changes. Second, as already reported by Heckman and Pagés (2000) and Gill, Montenegro and Dömeland (2001), among others, México's Federal labour law and labour unions are factors underlying the low responsiveness of employment to output fluctuations. Moreover, given that the Mexican labour market is characterized by the existence of a large informal sector, 20

\footnotetext{
20 It should be noted, however, that informal sector is not the same as informal employment. The informal sector is the unregulated sector whereas informal employment is the employment that does not have employment benefits, such as social security, health care, vacations, etc. A worker may have an informal job in a formal enterprise.
}

output fluctuations would induce labour mobility between the formal and informal employment without affecting open unemployment. All these elements - that is, changes in hours worked, labour productivity, heavy labour regulation and a large informal sector-operate in the same direction of lowering Okun's coefficient.

Third, to the extent that employment in the informal sector is characterized by low productivity, its contribution to overall GDP would be low indeed. Thus, the impact of a, say, reduction in unemployment on output would be significantly reduced.

Fourth, underreported revenues might bias the GDP estimates. Loayza and Sugawara (2009) showed that the size of the informal Mexican economy is about $30 \%$ of GDP, while the International Labour Organization (ILO, 1999), Schneider (2002) and Vuletin (2008) estimated that the size of the Mexican informal economy during the 1990 s ranged from $30 \%$ to $40 \%$ of GDP and employed more or less the same percentage of the labour force.

From a strictly Keynesian point of view, the relevant equation should be equation (10), where unemployment is the dependent variable and output is the independent one. Hence, the relevant coefficient is $\theta$ (see equation 12).

$$
\theta=-0.5226 \text { (standard deviation: }-0.039 \text { ) }
$$

As expected, the value of $\theta$ is not related to the value of $\lambda$. It measures the impact of a 1-percentage-point change in output growth on unemployment change. Obviously, much of the discussion about Mexico's labour market applies in this case. Another element that could explain the low correlation between the temporary components of output and unemployment is labour migration. To the extent that a large number of unemployed workers decide to migrate to the United States rather than stay at home, a given change in output would have a lower impact on registered unemployment rates for they will not show up in the unemployment statistics.

We now turn to the analysis of the correlation between the permanent components of output and unemployment. The relationship between the permanent innovations of output and unemployment rate can be examined in a way similar to traditional Okun's coefficient. Therefore, let be Okun's coefficient for permanent movements, we find that

$$
\gamma=\frac{\rho_{\eta_{y} \eta_{u}} \sigma_{\eta_{y}}}{\sigma_{\eta_{u}}}=-2.868 \text { (standard deviation: } 0.952 \text { ) }
$$

The resulting coefficient of the relationship between the permanent components of output and unemployment is also negative but higher than the one found for 
their transitory components. To the extent that this coefficient incorporates all short-run adjustments, we expect it to be larger than the conventional (short-run) Okun's coefficient. It seems that the unemployment

\section{VI}

\section{Conclusions}

The purpose of this essay was twofold: first, to estimate Okun's coefficient for the Mexican economy using a bivariate model that jointly estimates the permanent and temporary components of output and unemployment because this method provides unbiased and efficient estimates; and, second, to provide an economic interpretation of the parameters found. We have presented the two contrasting views of the nature of Mexico's labour market and argued that they are important in providing a proper explanation of the size of Okun's coefficient.

The methodology used allowed us to estimate two types of Okun's coefficient: a short-run coefficient which relates to the temporary component of output and unemployment, and a long-run coefficient which emerges when we correlate the permanent components of output and unemployment. Our results indicate that Okun's coefficient is much lower than previously estimated. We argue that this is to be expected, partly because of the existence of labour market rigidities and a large informal labour market, which reduces the impact of output growth on open unemployment rates. Another factor underlying this low coefficient is that labour unions severely restrain job creation during expansions and avoid job reductions during recessions. In the long run, a few other factors intervene in Mexico's labour rigidity caused by the existence of labour market rigidities and the informal labour sector present in the short-run is less binding over longer periods of time. market so that the size of the correlation between the permanent components of output and unemployment is larger than the short-run coefficient: namely, changes in capacity utilization, technical progress, the changing nature of the labour contracts, international migration and demographic changes. All of these elements seem to induce a higher coefficient. All of these issues remain open for future research.

In this study we have provided an estimate of Okun's coefficient at a given point in time; however, given the mounting evidence about the changing nature of Mexico's labour market, in particular, the increasing number of short term contracts and outsourcing arrangements, it is very likely that the coefficient has not remained constant. We suspect that the dynamic relationships of both the permanent and cyclical components have changed over time. This is particularly important because since the mid-1980s Mexico adopted a different economic strategy which has involved not only price and trade liberalization but also changes in labour-market institutions, among other things. Furthermore, there is the question of whether or not Okun's coefficient is symmetric, that is, whether or not we expect the impact of output growth on unemployment to be equal during expansions and recessions. 


\section{Bibliography}

Alcaraz, C. (2009), "Informal and formal labour fexibility in Mexico", Desarrollo y Sociedad, No. 63, Bogota, Centre for Economic Development Studies (CEDE).

Alcaraz, C., D. Chiquiar and M. Ramos-Francia (2008), "Diferenciales salariales intersectoriales y el cambio en la composición del empleo urbano de la economía mexicana en 2001-2004", Documentos de Investigación, No. 2008-06, Mexico City, Banco de México.

Alogoskoufis, G. and A. Manning (1988), "Wage setting and unemployment persistence in Europe, Japan and the USA", European Economic Review, vol. 32, No. 3, Amsterdam, Elsevier.

Balakrishnan, R., M. Das and P. Kannan (2010), "La dinámica del desempleo durante las recesiones y las recuperaciones: La Ley de Okun como punto de partida", Perspectivas de la economía mundial, Washington, D.C., International Monetary Fund.

Barreto, H. and F. Howland (1993), "There are two Okun's law relationships between output and unemployment", Crawfordsville, Wabash College.

Blanchard, O. and D. Quah (1989), "The dynamic effects of aggregate demand and supply disturbances", American Economic Review, vol. 79, No. 4, Nashville, Tennessee, American Economic Association.

Calderón, A. (2000), "Job stability and labor mobility in Urban Mexico: a study based on duration models and transition analysis", Research Department Publications, No. 3117, Washington, D.C., Inter-American Development Bank.

Cazes, S., S. Verick and F. Al Hussami (2011), "Diverging trends in unemployment in the United States and Europe: evidence from Okun's law and the global financial crisis", Employment Working Paper, No. 106, Geneva, International Labour Office.

Chavarín, R. (2001), "El costo del desempleo medido en producto. Una revisión empírica de la ley de Okun para México", El Trimestre Económico, vol. 68, No. 270, Mexico City, Fondo de Cultura Económica.

Clark, P. (1989), "Trend reversion in real output and unemployment", Journal of Econometrics", vol. 40, No. 1, Amsterdam, Elsevier. (1987), "The cyclical component of U.S. economic activity", Quarterly Journal of Economics, vol. 102, No. 4, Cambridge, Massachusetts, The MIT Press, November.

Crespo, J. (2003), "Okun's law revisited", Oxford Bulletin of Economics and Statistics, vol. 65, No. 4, Wiley.

De la Garza, E. (2005), "La flexibilidad del trabajo en México" [online] http://docencia.izt.uam.mx/egt/publicaciones/articulos/ flexibilidad.pdf.

Durbin, J. and S. Koopman (2001), Time Series Analysis by State Space Methods, New York, Oxford University Press.

Evans, G.W. (1989), "Output and unemployment dynamics in the United States: 1950-1985”, Journal of Applied Econometrics, vol. 4, No. 3, John Wiley \& Sons, Ltd.

Freeman, D.G. (2001), "Panel test of Okun's law for ten industrial countries", Economic Inquiry, vol. 39, No. 4, Wiley.

Gill, I., C. Montenegro and D. Dömeland (eds.) (2001), "Crafting Labor Policy: Techniques and Lessons Learned from Latin America", Washington, D.C., World Bank.

González Anaya, J. (2002), "Labor Market Flexibility in Thirteen Latin American Countries and the United States: Revisiting and Expanding Okun Coefficients", sciD Working Paper, No. 136, Stanford University, June.

Heckman, J. and C. Pagés (2000), "The Cost of Job Security Regulation: Evidence From Latin American Labor Markets", NBER Working Paper, No. 7773, Cambridge, Massachusetts, National Bureau of Economic Research.

Hwa, K., E. Zivot and D. Creal (2006), "The relationship between the Beveridge-Nelson decomposition and unobserved components models with correlated shocks", Working Papers, No. UWEC-2006-16-FC, Seattle, University of Washington.

ILO (International Labour Organization) (1999), Panorama laboral 1999, Lima.
Jardin, M. and S. Gaétan (2011), "How Okun's law is non-linear in Europe: a semi-parametric approach", Rennes, University of Rennes 1 - CREM, May.

Knotek, E.S. (2007), "How useful is Okuns's law?", Economic Review, Kansas, Federal Reserve Bank of Kansas City.

Koopman, S. (1997), "Exact initial Kalman filtering and smoothing for non-stationary time series models", Journal of the American Statistical Association, vol. 92, No. 440, Taylor \& Francis.

Lee, J. (2000), “The robustness of Okun's law: evidence from OECD countries", Journal of Macroeconomics, vol. 22, No. 2 , Amsterdam, Elsevier.

Lee, J. and M. Strazicich (2003), "Minimum Lagrange multiplier unit root test with two structural breaks", The Review of Economics and Statistics, vol. 85, No. 4, Cambridge, Massachusetts, The MIT Press.

Loayza, N. and N. Sugawara (2009), "El sector informal en México: Hechos y explicaciones fundamentales", El Trimestre Económico, vol. 76, No. 4, Mexico City, Fondo de Cultura Económica.

Loria, E. and M. Ramos (2007), "La ley de Okun: Una relectura para México, 1970-2004”, Estudios Económicos, vol. 22, No. 1, Mexico City, El Colegio de México.

Marshall, A. (2004), "Labour market policies and regulations in Argentina, Brazil and Mexico: programmes and impacts", Buenos Aires, National Council of Scientific and Technical Research/ Institute of Economic and Social Development.

Morley, J.C. (2007), "The slow adjustment of aggregate consumption to permanent income", Journal of Money, Credit, and Banking, vol. 39, No. 2-3, Blackwell Publishing.

Morley, J.C., C.R. Nelson and E. Zivot (2003), "Why are the BeveridgeNelson and unobserved components decompositions of GDP so different?", Review of Economics and Statistics, vol. 85, No. 2, Cambridge, Massachusetts, The MIT Press.

Nelson, C.R. and C.I. Plosser (1982), "Trends and random walks in macroeconomic time series: some evidence and implications", Journal of Monetary Economics, vol. 10, No. 2 Amsterdam, Elsevier.

Nelson, C.R. and R. Startz (2007), "The zero-information-limit condition and spurious inference in weakly identified models", Journal of Econometrics, vol. 138, No. 1, Amsterdam, Elsevier.

Okun, A.M. (1962), "Potential GNP: its measurement and significance", Proceedings of the Business and Economic Statistics Section, Washington, D.C., American Statistical Association.

Prachowny, M. (1993), "Okun's law: theoretical foundations and revised estimates", Review of Economics and Statistics, vol. 75, No. 2, Cambridge, Massachusetts, The MIT Press, May.

Schleicher, Ch. (2003), "Structural time-series models with common trends and common cycles", University of British Columbia.

Schnabel, Gert (2002), “Output trends and Okun's law”, BIS Working Papers, No. 111, Basel, Bank for International Settlements, April.

Schneider, F. (2002), "Size and measurement of the informal economy in 110 countries around the world", Washington, D.C., World Bank.

Sinclair, T. (2009), "The relationships between permanent and transitory movements in U.S. output and the unemployment rate", Journal of Money Credit and Banking, vol. 41, No. 2-3, Blackwell Publishing, March-April.

Sögner, L. and A. Stiassny (2000), “A cross-country study on Okun's law”, Working Paper Series, No. 13, Vienna, Vienna University of Economics and Business.

Vuletin, G. (2008), "Measuring the informal economy in Latin America and the Caribbean", IMF Working Paper, No. 08/102, Washington, D.C., International Monetary Fund.

Watson, M.W. (1986), "Univariate detrending methods with stochastic trends", Journal of Monetary Economics, vol. 18, No. 1, Amsterdam, Elsevier.

Weber, C. (1995), "Cyclical output, cyclical unemployment and Okun's coefficient: a new approach", Journal of Applied Econometrics, vol. 10, No. 4, John Wiley \& Sons, Ltd. 